\title{
Some Remarks on the Estimation of Informal Economy in the Republic of Macedonia
}

\author{
Dashmir Asani ${ }^{1}$, Dode Prenga ${ }^{2}$, Elmira Kushta ${ }^{3}$ \\ ${ }^{1} \mathrm{PhD}$ student, Department of Informatics and Statistics, Faculty of Economy, University of Tirana, Albania \\ ${ }^{2}$ Department of Physics, Faculty of Natural Sciences, University of Tirana, Albania \\ ${ }^{3}$ Department of Mathematics, Faculty of Technical Sciences, University "Ismail Qemali”, Vlora, Albania,
}

\begin{abstract}
In this paper we discuss some findings on the estimation of the informal economy in a particular economical system, the Republic of Macedonia. We observed that undeviating application of standard models were likely to produce inconsistent results and therefore some preliminary analytic precaution have to been taken. We obtained that the set of variables that mostly influenced the informality and shadow economy could be assigned by a step by step selecting procedure, instead of straight CDA or MIMIC model application. Next we assumed that the nature of influence for each variable could be proofed and not implemented by general arguments. Finally the calculations were performed for time intervals when the overall state appeared to be more relaxed. By performing in this way a step by step analysis we concluded in acceptable values and in the evidencing of dominant factors that simulate informal economy for the country. Not surprisingly a non-model variable-remittances-has been evidenced as an important factor. The work reveals the importance of model's basic assumption fulfilling in the case of economic systems where observables are non-stationary and the economy itself is typically in dynamical evolution. As result of such improvement of the procedure we obtained that the country's informal economy is going slight down starting from a local peak value touched in 2010-2011. By now it is stabilized around the values 33\%-35\% of GDP. We obtained herein that the majority of economic and political measures undertaken recently in the framework of informality reduction have worked in the aimed direction. From the factor point of view we obtained that contribution of some variables in the informal economy growth have been very specific and even contrarily to the expatiation for the period analyzed, that highlighted the importance of direct and continues calculation rather than judging from general perspective approaches.
\end{abstract}

Keywords: Informal and shadow economy, currency demand approach, taxation policy, MIMIC model.

\section{Introduction}

Informal economy is defined as part of a country's economy that is not observable in the sense of state fiscal activities. In a more detailed discussion [1], [2] this definition is reserved only for the part of unregistered economy that is created as result of evading formal official records to simply escape the Taxes' duties. There is another part of unregistered economy that could originate from criminal activities [3] which is expected to have different structure. A more general concept for those unregistered economical activates is encapsulated in the definition "shadow or underground economy". In the analysis of the informal economy there are two major objectives: estimation of the size and identification of factors that cause it to exits. In this view, researchers have evidenced the fact that the un-registered is tractable however, and therefore it can be estimated making use some theoretical 
relationship with its indicators. Moreover, factors and causes of informality can be analyzed in this process too. In econometrics it is believed that the existence of informal economy causes discrepancies, distortions for many economic parameters as compared to their expected values. So, it might cause a part unemployment force to be concealed, can cause the consumption to be higher than production or the money in circulation to be larger than expected. Accordingly this unseen economic quantity has been modeled and estimated [1], [2] etc., by simple regression techniques.. Direct and indirect methods have been proposed but each one has its advantages and disadvantages.[1], [4] Practical evidences show that obtaining an appropriate model and fixing the set for variables in each one of them depends on concrete economy under study as seen ne [5], [6], [7] an many others considerations. If data records fulfill some necessary requirements, the first evidence and the easiest way to estimate the informal economy is considered the method of "the GDP discrepancy". It states that the difference between GDP calculated by consumption and incomes give the informal economy

$$
G D P_{\text {Informal }}=G D P_{\text {Expenditures }}-G D P_{\text {Incomes }}
$$

In the reference[1] it is highlighted that results of the equation (1) would be admissible if data used in it would have been recorded carefully and without any subjective distortion. Therein is noticed that usually it didn't happen, therefore when using (1) the error should not be neglected. Other discrepancies methods based on physical outputs do need again adequate databases. Nevertheless, some of those methods are complicated and their techniques of calculation seem to be questionable in some critical point of view. But in any sense, discrepancies have been largely considered as indirect indicators and traces of the Informal economy and therefore they have been acknowledged as the basis of direct calculation of the informal economy. In this category have been listed discrepancy of unemployment rate, electricity use etc.[1],[3] etc. Aside those direct methods, some indirect techniques have been found more useful. So using simple currency ratio (SCR) by simple formula.[2]

$$
G D P_{i}=G D P_{f} \frac{C-\alpha_{f} D}{\left(\alpha_{f}+1\right) D}
$$

where $\mathrm{C}$ and $\mathrm{D}$ are respectively the currency in circulation and the Deposits, indices $i$ and $f$ stand for "informal" and "formal" whereas $\alpha_{f}=\frac{C_{f}}{D_{f}}$ The calculation according (2) is straightforward and is detailed in[1] etc. The confidence of the estimation (2) depends on two elements: the stationary of the series which we discussed especially in [11] and the rigorousness of the assumption that in actual economy velocities of the money in formal and informal sector are equal. Moreover the problems of zero informality time as by direct modeling in[1] would mostly affect the calculation in the case of transitory economies. Next, another technique called the currency demand approach (CDA) with following formulae or its derivative have been used largely:

$$
\ln \frac{C}{M_{t}}=\alpha_{i} \ln G D P_{t}+\beta \log \left(1+\operatorname{Tax}_{t}\right)-\gamma R_{t}+\varepsilon
$$

Here $\mathrm{M}$ is narrow/broad money, $\mathrm{C}$ the money in circulation, Tax is the average tax rate and $\mathrm{R}$ is the interest rate for Deposits. Again informal economy is supposed to be proportional to the extended demand for money and therefore the assumption of equal money velocity is taken as true. In applications (1), (2) and other similar, the informal economy is modeled as linear form (or log linear) of some factors (cause variables). Generally speaking, if a candidate-factor included in the forms (1), (2) etc., has a good regression statistics, one agrees that it is a cause for informal economy. A more complex method but probability more effective is the MIMIC model that put the informal economy in the middle point between factors and indicators. It looks like following 


$$
\begin{aligned}
& \left(\begin{array}{l}
G D P \\
\text { IndicatorY. }
\end{array}\right)=\Gamma G D P_{-} \text {Informal }+\varepsilon \\
& =\Gamma\left(\begin{array}{l}
\text { Tax.Rate } \\
\text { Unemplyment } \\
\text { GNI_Capita } \\
\text { FactorX }
\end{array}\right)+\eta
\end{aligned}
$$

where in IndicatorY could be placed any macroeconomic index areas in FactorX could be whichever economic parameter or variable. In general, factors are parameters like Taxes, tariffs, the incomes, wages, contributions, a quantifier of the structure of the capital for the country, political performance, and many others. Informal or shadow economy plays the role of the intermediate transcript between sides of relation (4), starting as response variable for the set of factors, and becoming factor variable for final indicators. Therefore a double regression is needed in this case which inevitably needs for more careful procedures as have been developed in [8], [9] etc. Apparently the mathematical nature of the series of variables is expected to affect the estimation. This aspect is taken into consideration in our calculation. Finally, another source of incertitude in the evaluation of the latent variable under examination is related to the real structure of the unregistered economy. So, the presence of criminal or similar activities that contribute in the shadow economy is inevitable and this last cannot be modeled so the overall calculation became complicated [10]. As a result, by direct implementation of the standard modeling it is arguable that values obtained could not be always satisfactory or even realistic. Based on those remarks, we have anticipated the applications of linear models mentioned herein by analyzing each element discussed in this introduction.

\section{Some findings using direct and indirect methods}

The economy of Republic of Macedonia has known an energetic change at 1990 when the system has been transformed toward the market economy. In this sense it is expected that the variables representing economic observables have been highly dynamical during the afterwards period. We commented this feature in our recent work. ${ }^{[11]}$ We acknowledge that during [1990, 2016], methodical improvement in public database have been applied consecutively until a full modernized methodology has been adopted by the end of $2010 .{ }^{[12],[13]}$ In this view we expected that linear modeling of the informal economy might have considerable incertitude or other incompatibilities due the lack of fulfilling of some assumptions. In our first calculation we observed that the literally application of standard models leads to different results. From the other side, it happen that an observable that does not appear as factor in the regressions of the type (3) or (4), has been identified as related with informal economy calculated using another model. Hence we addressed them in the followings.

\subsection{Avoiding premature conclusions using different approach}

The estimation of the informal economy for the Republic of Macedonia up to 2008 has been reported consecutively as seen in[13],[14] or in a more general view as in.[16] In our work we considered the evaluation of this parameter for a narrow period of time defined as [2004, 2016]. Some specifics of the calculation for this period were reported in.[11] Herein, we are interested on the size of informal economy and the effect of some factors on it. We have analyzed many of them, but purposely we will discuss the corruption effect on the informal economy. In this approach we considered the calculation of the informal economy using discrepancies models and used those estimations to check the possible relationship between the latent variable and factor-like ones. The most highlighted finding we observed for some categorical variables which we will discuss shortly below. When applying unemployment model of informal economy using yearly data we obtained that the result is quite similar with the estimation using GDP discrepancies as seen in the Figure 1.a. It has the same trend as the corruption index as seen in the Figure 1.b. Therefore in mechanical view, this variable is expected to influence our latent variable. In practice, there is a common belief that correlation is indicator of causative. 


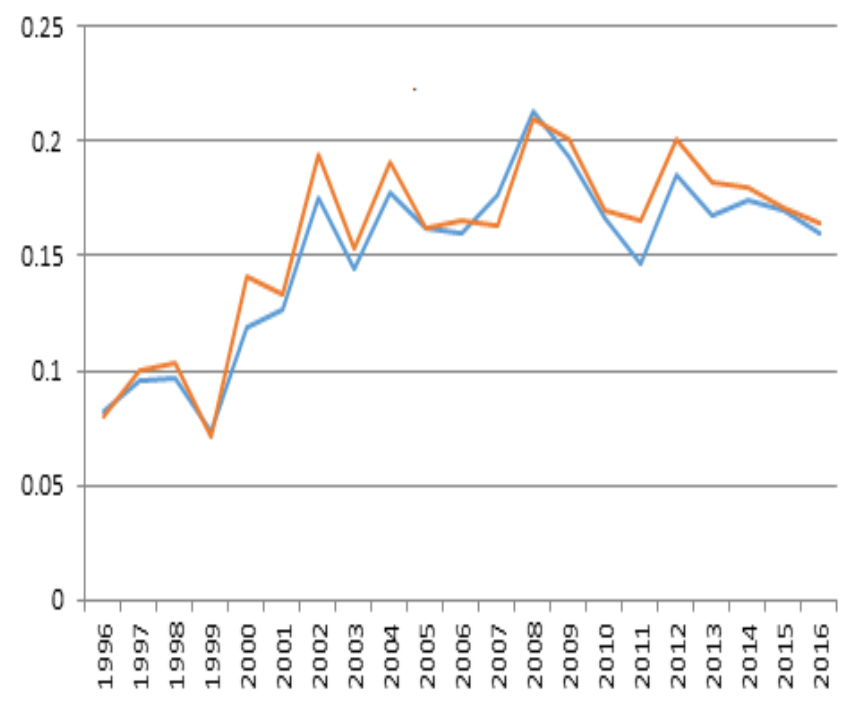

a. Percent of Informal GDP. Orange line, according to GDP discrepancies, blue line, according to Unemployment model

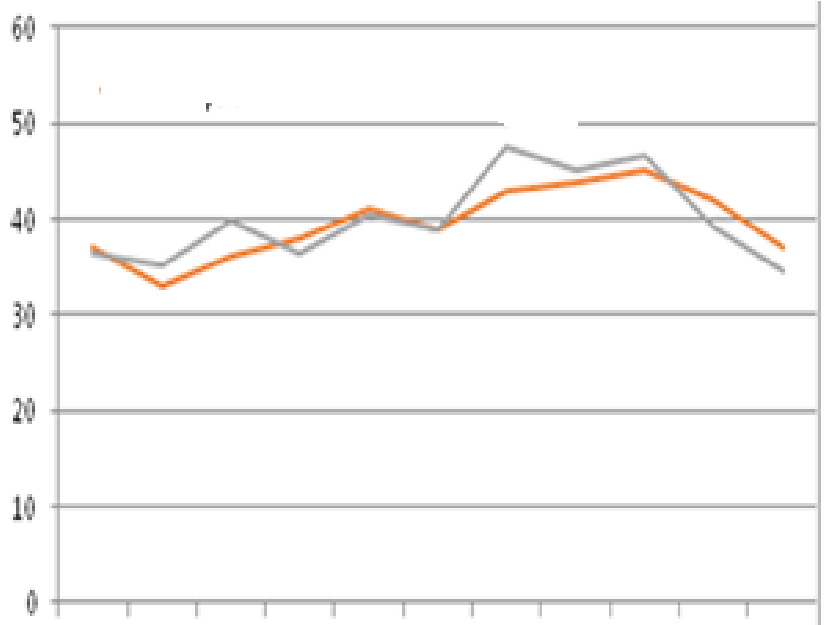

20062007200820092010201120122013201420152016

b. Relativized Corruption index (orange line) and Informal Economy (black line)

\section{Figure 1: Informal economy and the corruption index}

The same result is obtained in the case of the variable measuring administrative performance of the government as the ratio Budget Deficit/GDP. In our analysis we commented those findings as indicators for possible relationship but more proof is needed to conclude. Next we use the linear modeling of the type (3) extended as discussed in [18] and other models of type (4) using forms suggested on the literature. We obtained that the regression and the statistics for the variable "index of corruption" didn't confirm the direct relationship with informal economy and therefore the high positive correlation seen in the Figure 1 is considered as false in our case. In general this is not novel as seen in [17]. This suggested that the discrepancies method is not accurate and should be revisited. The other possible reasons could be the nature of categorical variable. Similar results have been obtained for the other parameter analyzed the quality (performance) economical governance. Adding to the remarks above, in this case we proposed to use more tinny series based on quarter or even monthly data. But from our actual system perspective, we supposed that linear models would be applied if there is no regime change in the period examined, so it would have been checked with priority.

\subsection{Identification of the best interval where a linear model is reasonably applicable}

We analyzed the set of variables proposed in [1] in the framework of CDA or MIMIC model. The trend of variables (logarithmic variables) showed two special points, one was located around 1990 and the other one in the zone [2002, 2004]. We observed that the behavior of the informal economy calculated using Cagan model as given in [1] etc., clearly differs to the one variable that is expected to be co-linear, as the rate of unemployment or example, Figure 2.a. Using the reviewed CDA model proposed by Tanzi, we obtained the same behavior which support the evidence of a strong change in-betweens the years 2002-2004. Therefore, this consists in a special point that should have been avoided form the series used in linear forms as (3). Moreover, the estimation with CDA in the full interval [1998, 2014] showed an undervaluation of informal economy, because the level of $20 \%$ is characteristic for the developed country as reported in [7] which is not our case. We thought that the major cause for the inconsistencies of the value of informal economy estimated for interval [1998, 2014] as evidenced in Figure 2 was related to apparently regime change in 2002 . So, a better tactic for linear regression would have been the use of data series that do not included records from this time zone. 


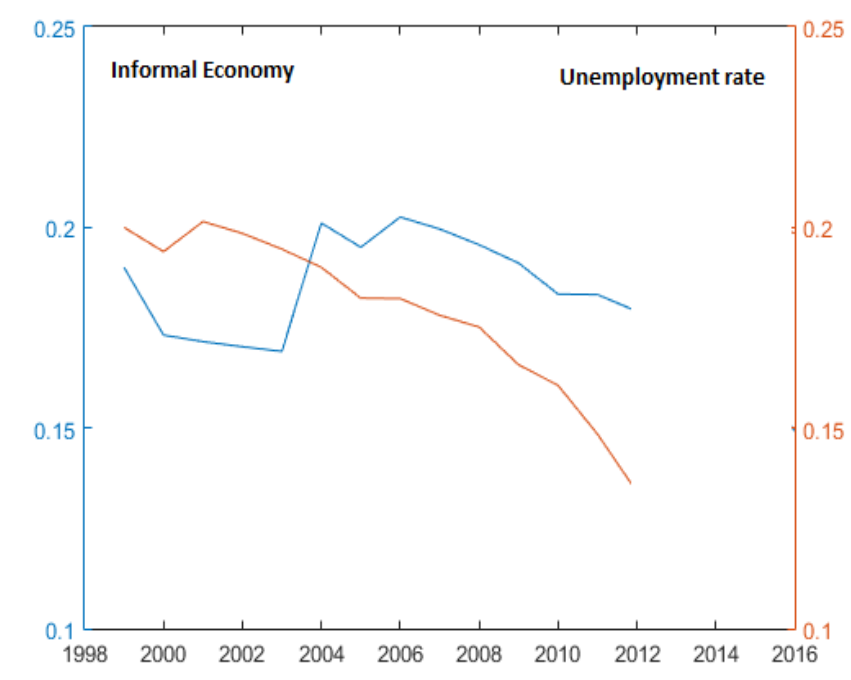

a. Informal Economy by Unemployment method

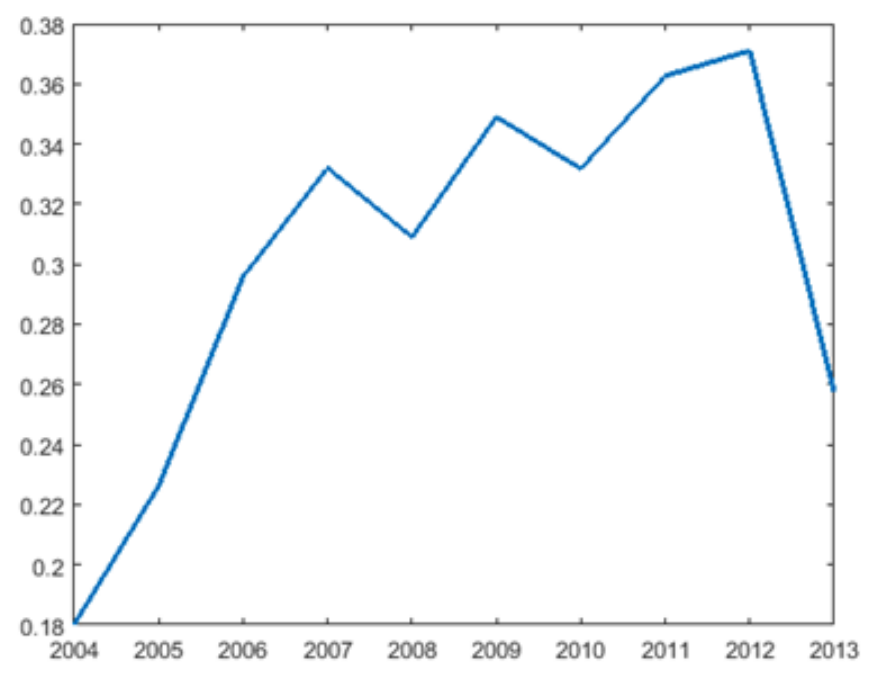

b. Informal economy by CDA in Tanzi version

\section{Figure 2: Informal economy by different models}

By such a correction of the reference interval we have improved the calculated the informal economy in the period [2004, 2014] as given in Figure 2.b. In this case we obtained a high value of it around 38\% of GDP near 2010-2011 and a decreasing trend form this date as seen in the Figure 2.b. the average level of informal economy has been found higher than $20 \%$ and this result has been supported by other models too.

\subsection{Assessment of typical variables representing particular categories on models}

Another issue has been initiated from unexpected findings for the effects of some factors. So, in calculation of the type (3) coefficient of linear regressions for some categories of Taxes were found negative that seems to be a meaningless result. In principle this is possible as discussed in the reference [2], [3] and others because economical systems are complicated in the best approach, and sometimes behave as complex in the full sense. A corollary of this property is that there is no rigid model for all cases, as is proven to be true in many applications. In such a case we operated according tactics mentioned above to exclude "exterior troubles". Next we extended the idea of an adaptive application of the models recommended in the literature as [6] or [5] by considering a set of variables for each category involved in equations of the type (3) or (4). Thus, we searched empirically to find which concrete variable could be exactly in the role described by the appropriate category in the equation. So, in CDA model the variable "Taxes" appears in relation as $\ln (1+$ Tax.Rate) [1]; variables "Interests Rates" appears directly in equation of the type (3), other parameters appear in logarithm Figures etc. Hereto we realized a generalized regression procedure of a linear approach for $\ln (\mathrm{C} / \mathrm{M})$ including all categories of variables and all variables under examination. The series that "survive" statistical test for regressions including a satisfactory ratio of error to the average value evaluated as seen in Table 1, have been qualified as the appropriate term for final calculation within the model of the type (3) or (4).

Table 1: Typical factors

\begin{tabular}{llllll} 
& & Value & Error & T sat & pValue \\
\hline $\begin{array}{l}\text { Average } \\
\text { Taxes rate }\end{array}$ & Intercept & -1.9738 & 0.15995 & 12.34 & $2.25 E-07$ \\
\multirow{4}{*}{ VAT } & & & & & \\
& Elasticity & 5.9286 & 3.0365 & 1.9524 & 0.079429 \\
Total Taxes & Intercept & -4.999 & 1.1046 & 4.5256 & 0.001099 \\
& Elasticity & 20.602 & 6.8664 & 3.0004 & 0.013335 \\
& Intercept & -5.6745 & 1.1329 & 5.009 & 0.00053 \\
& Elasticity & 26.723 & 7.5881 & 3.5217 & 0.005522
\end{tabular}

In the Table 1 we observed that all variables in the regressions have good pvalues, but VAT has a good error to value ratio and good statistical fitting parameters. The variable "Average Taxes" that appears in standard models of the type (3) and its Tanzi equivalents seems to be not the best choices. In the other side, the VAT has good statistics (pvalue is obtained lower than standard thresholds) and good error to vale ratio. Moreover, we obtained that in some regressions of type (3) 
the coefficient of the term $\ln (1+$ AverageTaxRate $)$ has negative value that is theoretically wrong. The two other terms including VAT or Total Taxes have had positive sign in the regression so each one could play the role of "Taxes" in theoretical model. Taxes are expected to simulate the informal economy so the sign should be positive. In the same way we have to decide which element of the category "Interest Rate" plays the role of the Interest rate for Deposit as an expected inhibitor effect in informality in original model and so on.

\subsection{Remarks for the variable of type currency}

The last element we addressed herein was the Indicator variable. In theory the indicator of informal economy is money aggregate. The question herein is to identify which one of them represents at the best the informality for the economy. Again, the direct use of series has given acceptable values but not consistent with some expectation. The most important indicator for informal economy is the currency out of deposits [1] so we discussed it more thoroughly. We considered the fact that the amount of money entering in cash the country in the form of remittances is considerable, ${ }^{[19],[20]}$ In general, those inputs are found usually in Euro currency which has been used as payment tool as well, behaving temporally as national currency itself (Denar) and therefore we proposed to use it as part of total money in circulation by replacing $\mathrm{C} / \mathrm{C}+\mathrm{R}$ in the CDA model. Notice that by direct use of models we obtained a lower than expected level of informal economy whereas if including remittances in $\mathrm{C}$ in has shifted up by a few percent. But the most intriguing part of these discussions comes from finding represented in the Figure 3.a where it is seen that $C / D$ has a decreasing trend in all the period [2001, 2015] whereas it is supposed to be proportional to the informal economy.

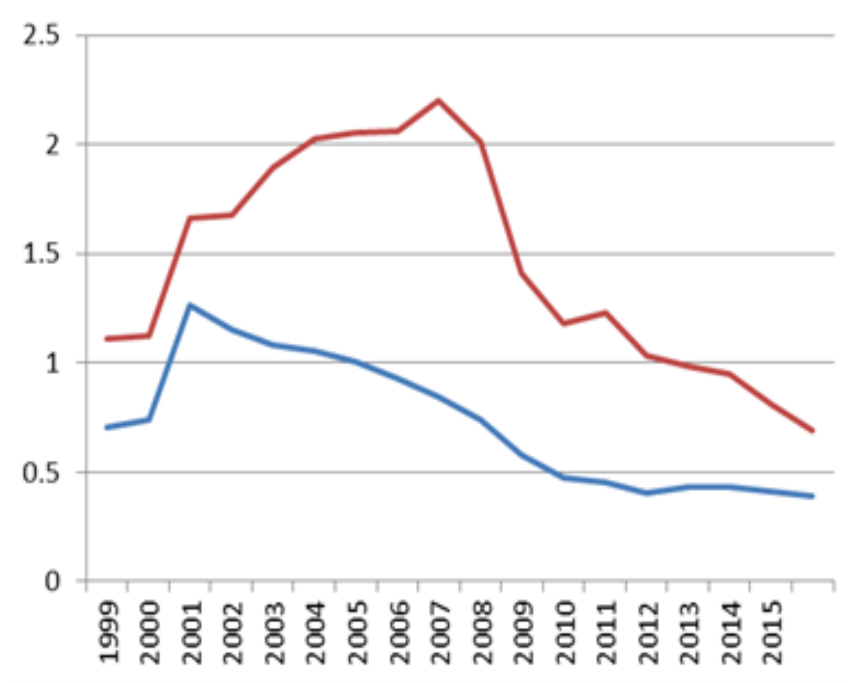

a. By red line, the ratio of Currency (C)+Remittance to Deposits (D); blue line, C/D ratio

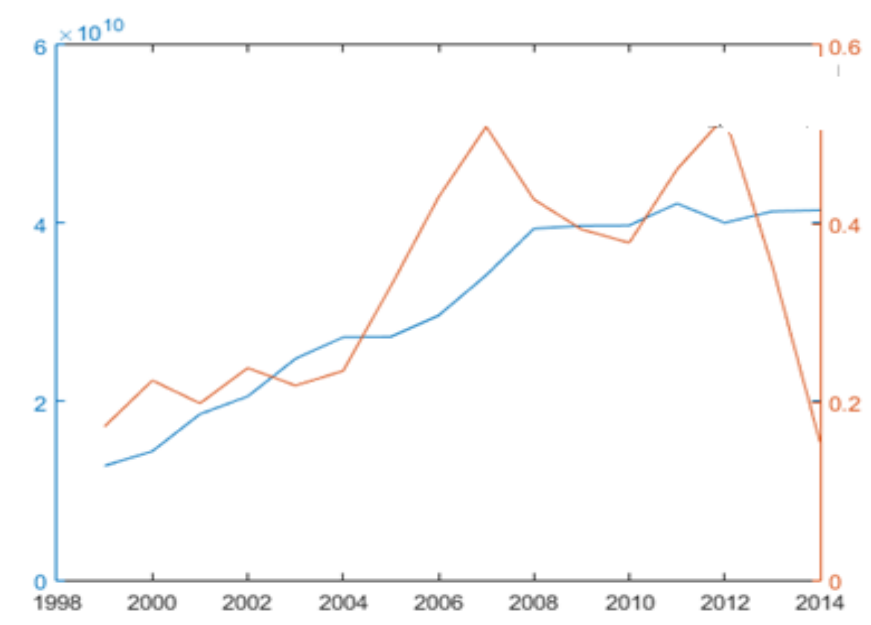

b. In orange, informal economy by simple Cagan model. Blue line, Currency + Remittances

\section{Figure 3: Role of remittances in the simply monetary models.}

This last was not reported to show constant decreasing trend in this period and therefore the initially assumed indicator variable C/D would better be $(\mathrm{C}+\mathrm{R}) / \mathrm{D}$. Hereby we noticed the improvement of the calculation but again the change from year to year is high, in some case around 5\% that is not theoretically supported. This last remark suggests again the use of tiniest series which we reported in. ${ }^{[11]}$

\section{Calculation of informal economy for the Republic of Macedonia}

We have considered all precaution steps analyzed above in the final estimation of the informal 
economy of the Republic of Macedonia. The opportune period for calculation in [1996, 2016] is considered the narrower interval [2004, 2014]. Other findings and comments considered have been reported in [11] as typical for the application of linear models, CDA, SCR or even MIMIC in our concrete system. Next the variables being qualified as more representative of a category related to the linear form (3) have been used in the calculation based on simple currency ration (SCR) and Currency Demand Approach. The result showed significant improvement on the determination of major causes for informal economy in the country. Consequently we were able to better selection of the set of variables to be used as factors and indicators in the more advanced MIMIC model. We observed that those steps improved the calculation.

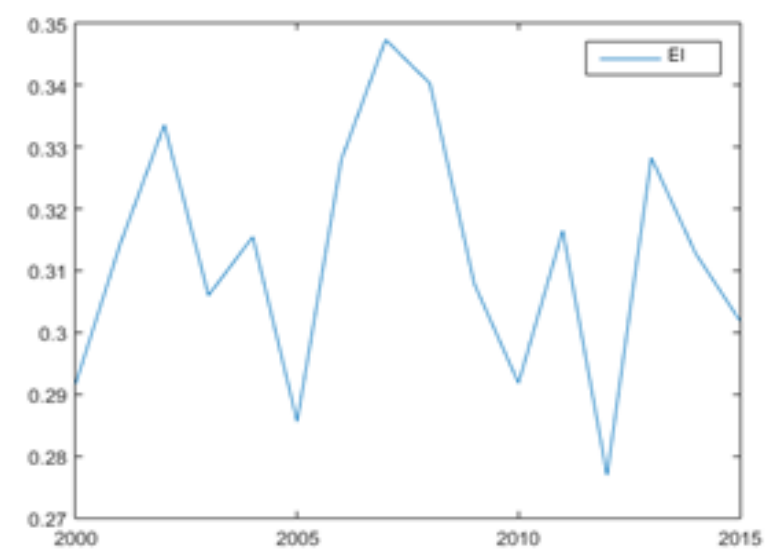

a. Informal Economy by MIMIC 8-1-3 model :

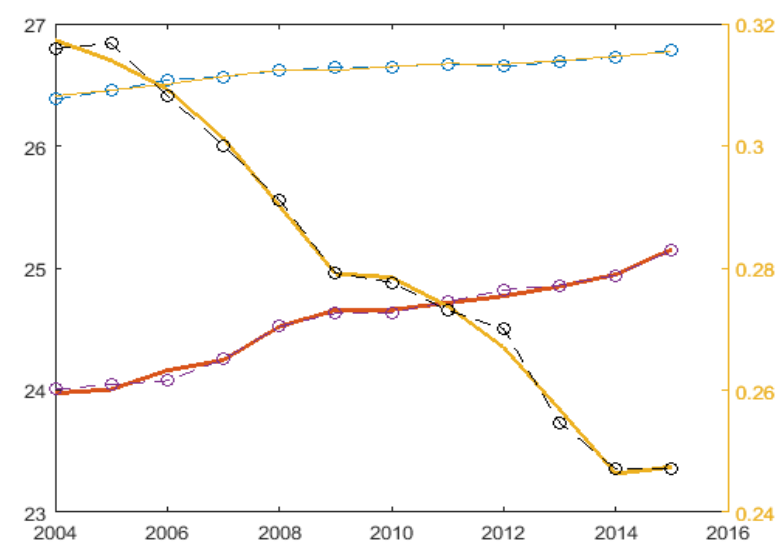

b. Reproduction of the indicators: yellow line, unemployment rate, blue line, $\ln (\mathrm{GDP})$; red line logarithm of narrow money,

Figure 4: Informal Economy estimated by MIMIC model
Now the latent variable showed slighter changes say around $1 \%-3 \%$ from year to year and moreover the reproduction of the indicators based in model's parameters is obtained qualitatively good (quite correct in logarithmic scale) as seen in the Figure 4.b. Next, the full analysis of the system has been performed straightforwardly. Thus, variables as Remittances, GDP per capita, VAT, GDP deflator, Taxes over Personal Incomes, and Interest Rates of Deposits have been identified as key factor in the size of the informal economy for the country. Indicators of the informal economy were identified to be the GDP per Capita, the Narrow money M1 and the Rate of Unemployment. The unregistered economy has reached $35 \%$ of the GDP near the year 2010 and now is around $31-33 \%$ of the GDP. Oscillations continue to be present on the trend of the annuals value estimated, so the analysis needs for more improvement which remains to be addressed in our future works.

\section{Conclusions}

We realized to find the most appropriate time interval to implement linear modeling in the calculation of the informal economy for Republic of the Macedonia. We obtained that the set of variables that mostly influenced the informality and shadow economy could be assigned by a step by step selecting procedure. In particular, we observed that the corruption and economic performance of the government have a complicated effect, whereas Remittances, Value Added Taxes, Taxes in the Incomes, Interest of Deposits and GDP acts as a set of factors that are responsible for the size of informal economy for the period [2004,20014]. We identified GDP per Capita, the Narrow Money and the Unemployment as key indicator of the informal economy for the period exanimated. The underlined trend of informal economy for the country in the period [2004, 2014] showed the peaks at 35\%-38\% around the year 2010 and now it is decreasing toward a stationary state to the around $33 \%$ of the gross national production. We obtained herein that the majority of economic and political measures undertaken recently in the 
framework of informality reduction have worked in the aimed direction. From dynamical point of view we obtained that the overall contribution of some variables in the informal economy is complex and therefore their quantitative weight would probably change in the future.

\section{References}

[1] Schneider, Friedrich and Willimas, Colin C., The Shadow Economy (June 1, 2013). Institute of Economic Affairs, 2013.

[2] F. Shneider, R. Dell'Ano. Estimating the underground economy by using mimic models: a response to T. Breusch's critique by dell'Ano, Working paper no. 0607. July 2006

[3] Guerino Ardizzi, Carmelo Petraglia, Masimiliano Piacenza, Gilberto Turati. Measuring the underground economy with the currency demand approach a reinterpretation of the methodology, with an application to Italy. https://econpapers.repec.org/RePEc:bla:re vinw:v:60:y:2014:i:4:p:747-772

[4] Roberto dell'Anno, Ong Helen Solomon. Shadow economy and unemployment rate in U.S.A. Is there a structural relationship? An empirical analysis. Applied Economics, Taylor \& Francis (Routledge), 2008, 40 (19), pp.2537-2555.

[5] Ademola Ariyo and William Bekoe. Currency Demand, the Underground Economy and Tax Evasion: The Case of Nigeria. Journal of Monetary and Economic Integration,. Vol. 11, No.2, pp129-157

[6] Friedrich Schneider, Fatih Savaan. Dymimic estimates of the size of shadow economies of Turkey and of her neighboring countries. International research journal of finance and economics .January 2007

[7] Friedrich Schneider, Andreas Buehn, Claudio E. Montenegro. Shadow economies all over the world. New estimates for 162 countries from 1999 to 2007. Policy research working paper 5356
[8] Peter Michale von der Lipe. Measurement and Relevance of the Shadow Economy inthe European Union. Symposium at the Uni versity of Wuhan/China April $1-4$, 2009

[9] Ramona Angelescu, Laura Chappell. Alex Glennie, George Mavrotas, Dhananjayan Sriskandarajah. Measuring and Optimizing the Economic and Social Impacts of Migration in the Republic of Macedonia. Development on the Move. IPPR-GDN. Skopje, 2009

[10] Dragan Đuri The Shadow Economy: Between Authority and Crime. SEER: Journal for Labour and Social Afairs in Eastern Europe. Vol. 2, No. 1 (April 1999), pp. 59-68

[11] Dashamir Asani, Dode Prenga. A practical strategy to improve econometric modeling-a case study for informal economy on the Republic of Macedonia. International Journal of Scientific Research and Management (IJSRM) Volume 6 Issue 7 [July 2018]

[12] https://www.finance.gov.mk/files/u6/y_of_ the_republic_of_macedonia_2010_2012_a ng.pdf

[13] http://www.mio.gov.mk/sites/default/files/ pbl_files/documents/reports/midterm_selfassessment_report_20162018_ogp_ap.pdf

[14] Biljana Davidovska-Stojanovska, Magdalena Petrovska, Aneta Krstevska, M.A. Analysis of the leve 1 of currency in circulation in the Republic of Macedonia and the reasons behind its high leve 1 . National Bank of the Republic of Macedonia. Research Department Working Paper No.11

[15] Ramona Angelescu, Laura Chappell. Alex Glennie, George Mavrotas, Dhananjayan Sriskandarajah. Measuring and Opetimising the Economic and Social Impacts of Migration in the Republic of Macedonia. Deve lopment on the Move. IPPR-GDN. Skopje, 2009 
[16] Rufi Osmani. The level of the shadow economy, tax evasion and corruption: the empirical evidencë for see countries.

[17] Axel Dreher $\bullet$ Friedrich Schneider. Corruption and the shadow economy: an empirical analysis. Public Choice (2010) 144: 215-238 DOI 10.1007/s11127-0099513-0

[18] Idrissa M. Ouédraogo. Governance, Corruption, and the Informal Economy .Modern Economy, 8, 256-271. https://doi.org/10.4236/me.2017.82018

[19] Dietz, Barabara (2010) : Migration and remittances in Macedonia: A review, Arbeiten aus dem Osteuropa-Institut Regensburg, No. 281, ISBN 978-3938980-30-9, Osteuropa-Institut Regensburg, Regensburg

[20] https://countryeconomy.com/demography/ migration/remittance/macedonia)

\section{Authors Profile}

Dashamir Asani, has graduated on Economy and has finished the research in framework of his $\mathrm{PhD}$ in management and marketing. His researches are focused on modeling informal economy and some application on concrete systems.

Dode Prenga, Professor Associate, Doctor in Operational Researches, has graduated in Physics on 1992 at the Faculty of Natural Sciences, University of Tirana. His major works are focused in the study of some real systems in the framework of complexity.

Elmira Kushta, has graduated in the 5-year Mathematics Branch on 1989 at the Faculty of Natural Sciences, University of Tirana.2010. She obtained the $\mathrm{PhD}$ degree on 2018 in the applied statistics. She started as lecturer of statistics in the Faculty of Technical Sciences, University of Vlore. Now she is working on statistical and operational researches and simulation for consumer behavior and marketing. 